\title{
El corazón del Evangelio en los márgenes del mundo Para una espiritualidad del martirio
}

\section{Luiz Carlos Susin*, Pontificia Universidad Católica de Río Grande del Sur, Brasil}

Mártir es el que da testimonio, el testigo que arriesga incluso su vida y su sangre. Juan es el evangelista que mejor expresa la dimensión martirial de Jesús, el testigo por excelencia de Dios, el Padre'. Visto desde esta perspectiva es espantoso y trágico lo que dice Juan en el comienzo de su Evangelio: "Vino a los suyos y los suyos no lo recibieron" (Jn 1, 11). Y si se tiene en cuenta la proclamación grandiosa y esperanzada que le procede, la constatación es sorprendente, totalmente inesperada y sin aparente lógica: "En el principio, la Palabra estaba en Dios y todo se hizo y tomó vida por la Palabra de Dios. Esa Palabra es la vida del mundo, la luz que alumbra en la oscuridad. Estaba en el mundo y el mundo fue hecho por ella, pero el mundo no la conoció. Vino para lo que era naturalmente suyo, pero los suyos no lo han recibido" ( $c f r$. Jn 1, 1-11). Y mataron a Jesús, la Palabra, amparándose en justificaciones legales. Pero Juan añade una segunda constatación que sí es una buena noticia. "A los que recibieron la Palabra de Dios, les dio poder de hacerse hijos de Dios, nacidos de Dios" ( $c f r$. Jn 1, 12s).

Siempre queda, sin embargo, la intrigante pregunta: ¿Por qué el mundo no conoce a su autor? ¿Por qué los suyos no lo han recibido? ¿Será mala voluntad o es algo estructural en este mundo?

* Luiz Carlos Susin, fraile capuchino, licenciado en filosofía y doctor en teología por la Universidad Gregoriana de Roma, es profesor en la Pontificia Universidad Católica de Río Grande del Sur, Brasil. Es también miembro del equipo de reflexión teológica de la Conferencia de los Religiosos de Brasil (CRB), miembro del equipo editorial de la Revista Internacional de Teología Concilium y secretario general del Foro Mundial de Teología y Liberación.

1. En este texto, más bien meditativo, nos fijaremos en el Evangelio de Juan desde su estructura interna. Cfr. J. Mateos y J. Barreto, El Evangelio de Juan. Análisis lingüístico y comentario exegético, Madrid, Cristiandad, 1979, 2. ${ }^{\text {a }}$ ed. 
Un poco más adelante, el versículo 14 del primer capítulo de Juan, tan conocido, nos revela y entrega el secreto de Dios: cuál es el lugar de su revelación y el lugar de encuentro con él. "La Palabra se hizo carne". En condición de fragilidad y de mortalidad, propias de la carne humana, se deja encontrar habitando entre nosotros, en tienda de beduino y peregrino, como la nuestra, pues eso somos al pasar por este mundo. Ese modo y lugar de revelación divina nos ponen, de nuevo, ante el espanto y la trágica posibilidad de no reconocer ni acoger el huésped divino.

Este es el escándalo del Evangelio, la piedra en el camino de la religión cristiana, como enseñó Pablo a los Corintios ( $c f r .1$ Cor 1, 17-31). Nunca se insistirá demasiado en este misterio, que es, a la vez, maravilla y escándalo. Es el corazón del Evangelio y lo específico cristiano en un mundo de muchas religiones, incluso de muchos cristianismos. La consecuencia es que, para conocer a Dios, la pregunta original y metodológicamente correcta no es la pregunta por su esencia, sino la pregunta por el lugar desde donde él decidió acercarse y revelarse a nosotros. Y aunque quedemos extasiados por una respuesta de Dios tan sorprendente y tan "humanizada", siempre queda la pregunta: ¿Por qué parece tan difícil aceptar esta "contra-lógica" divina? Quizás la respuesta tenga que ver con nosotros mismos, más que con Dios.

La respuesta nos conduce por caminos inesperados, tan sorprendentes como los caminos de Dios hacia nosotros. Y como por naturaleza, al menos en un primer momento, nos resistimos a caminar por esos caminos.

A continuación, vamos a examinar los dos movimientos: el que viene de Dios a nosotros y el que nos lleva a nosotros a Dios.

\section{La manera de acercarse Dios al mundo: el lado maravilloso}

Es pretensión querer saber cómo actúa Dios, cómo es Dios, cómo piensa Dios. Ese saber, ciertamente, no es especulación de una cabeza pensante. Son las fuentes cristianas y el hilo conductor de la mejor tradición cristiana los que dan testimonio de la forma del acercarse Dios al mundo.

El evangelista Juan pone diáfanamente ante nosotros el lado maravilloso de Dios: "Tanto amó Dios al mundo que entregó a su Hijo único" (Jn 3, 16). El Hijo no vino a condenar, sino a salvar al mundo ( $c f r$. Jn 3,17$)$. Y ni siquiera vino a juzgar, sino a salvar ( $c f r$. Jn 12, 47). Lucas y Mateo expresan ese acercamiento salvador en los relatos del nacimiento y la infancia del Mesías: nacido de una mujer, al cuidado de unos padres de condición humilde. Por ello, sin necesidad de considerar los detalles, la fiesta de Navidad siempre conmueve con la sorprendente humildad de Dios. ¿No es Dios el "Todopoderoso", del que se dice que posee todos los atributos del ser, del poder, del saber, del tener? El monoteísmo, ciertamente, afirma que solo al único Dios compete toda fuerza, toda sabiduría, 
toda riqueza, todo poder, toda gloria, honor y majestad. Todo le pertenece a él (cfr. Ap 5, 12s; Rm 16, 27; Judas 25).

Usando una metáfora espacial, estaríamos apuntando a lo alto: Dios está por encima de los ricos, de los poderosos, de los sabios, de aquellos que reciben más honores en este mundo. Y continuando con la lógica de la metáfora, estos, los más poderosos, los más ricos, los más sabios, son entonces los que estarían más cerca del Dios que está en lo alto. En este mundo de tanta desigualdad tendrían el privilegio de ser los signos de Dios más significativos. Cuanto más nos acercamos a un poderoso o a un rico, más nos estamos acercando a lo divino. Y de aquí proviene la fascinación de la riqueza, del poder.

Desde el Evangelio hay que reaccionar a este modo de ver las cosas, por supuesto. Algún problema se esconde en esta lógica y en esta metáfora. No es este el lugar privilegiado del acercamiento de Dios. Es cierto que hay textos en el Antiguo e incluso en el Nuevo Testamento que con toda claridad usan las metáforas de un Dios poderoso. Pero hay que releerlos y repensarlos. Entonces, podemos entender que son metáforas proféticas, que hablan de Dios en confrontación con los poderes y las majestades de este mundo y sus ídolos. Cuando se confiesa que todo el poder, toda la riqueza, todo el saber, todo honor y majestad, está concentrado en Dios, se relativiza y se abaja a los poderes de este mundo y a sus fascinantes ídolos. Estos poderes, en efecto, llevados a lo absoluto de ser divinizados, se tornan diabólicos, se convierten en el mal absoluto, en fuentes de injusticia, crueldad y sufrimiento de inocentes.

Pero aun con esta explicación, no es esta la metáfora mejor y más madura, la palabra más reveladora de Dios, de su manera de acercarse y de dejarse encontrar. Abandonadas a su suerte, por un lado, las metáforas de la omnipotencia, del poder y de la riqueza, tienen la finalidad de relativizar los poderes de este mundo, pero, por otro, poniendo a Dios por encima de los ídolos, terminan haciendo de él el ídolo mayor que somete a todos los demás. Dios sería "el más fuerte que aprisiona al fuerte" ( $c f r$. Mc 3, 27), pero se mantiene en la misma lógica de la crueldad típica de los ídolos. Y cuando se recurre a esta imagen de Dios, surgen todo tipo de preguntas y tentaciones: ¿por qué Dios no tiene fuerza o providencia para evitar un terremoto, un desastre, un sufrimiento inocente? ¿O para someter a los tiranos y a los sistemas injustos?

Pero se puede tomar la metáfora de la riqueza en un sentido más amplio: abundancia: Pablo es muy claro en su paradójica proclamación: "Conoced la gracia de nuestro Señor Jesucristo, que, siendo rico, por vosotros se hizo pobre, para enriqueceros con su pobreza" (2 Cor 8, 9). Observemos la sutileza de las palabras finales: no es, propiamente, para enriquecernos compartiendo su riqueza, sino compartiendo su pobreza, la pobreza en la que aprendió a ser humano como nosotros, pobres y frágiles, mortales. Él comparte su humanidad, 
y eso es lo verdaderamente divino en él. En otras palabras, según el himno que Pablo incluye en la carta a su querida comunidad de Filipos, aquí está la realidad de la kénosis ( $c f r$. Fl 2, 6-11), el vaciamiento de la condición divina, de la que, como misionero divino, podría reclamar su parte de divinidad. Se acerca en la carne y en el lenguaje humano, renuncia a la condición divina como tentación - aunque podría ser derecho suyo-, pues sería un espectáculo, una demostración de poder y majestad. La renuncia lo conduce por los caminos de peregrino humilde y obediente a los límites de lo humano, carente incluso y necesitado, que se acerca no como quien manda, sino como quien suplica y se pone a servir, "Dios Siervo", Dios "sub specie contrarii".

Utilizando de nuevo una metáfora espacial, es un Dios que renuncia a acercarse desde lo alto para acercarse desde abajo, desde un lugar más humilde que el lugar donde estamos. Hay siempre algo "pequeño" - elachístos, humillado, aplastado ( $c f r$. Mt 25) -, que es más pequeño que nosotros. Es el lugar donde Dios nos sorprende acercándosenos paradójicamente: para enriquecernos con su pobreza, suscitando en nosotros, en la relación con él, no la humillación de nuestra carencia ante su grandeza, sino la generosidad de nuestra iniciativa y creatividad, de nuestra ayuda y de nuestra ternura ante un Dios humilde.

Así fue Jesús en su acercamiento a Pedro y a los que pensaban que eran pecadores, a Zaqueo perdido en su riqueza y a Mateo en su espacio de poder, a la samaritana, pidiéndole agua. Y también en sus pequeños relatos, perlas donde resplandece la paradoja de que el acercamiento y la salvación ocurren desde abajo. Por lo tanto, mirando abajo reconoceremos a Dios. Y en la humildad de su solidaridad, recibiremos nuestra gloria. Como los pastores de Belén, considerados impuros por su trabajo con animales, pero envueltos en gloria y cánticos celestiales ( $c f r$. Lc 2, 8ss).

Esta novedad que invierte la mirada para buscar a Dios pronto se convirtió en sello distintivo del cristianismo: "Gloria maior Deus humilis". ¡La gloria mayor es un Dios humilde! De ese modo, los Padres de la Iglesia hicieron la distinción entre el Dios de Jesús y el Dios de los filósofos, aunque la lógica de los filósofos sobre Dios fuese fascinante. Que Dios sea grande, inmortal, omnipotente, fuerte, intocable, irrepresentable, es la imagen resultante de la lógica de lo que debe ser lo divino. Contiene una verdad lógica y transcendente sobre Dios y su gloria que puede ser pensada filosóficamente. Pero que Dios sea pequeño, mortal, frágil, pobre y suplicante, eso es una gloria aún mayor, una gloria y una lógica diferente, una experiencia de grandeza y de poder de otro orden, que no cabe en la lógica filosófica. En el mismo sentido, el papa actual, siendo todavía un joven teólogo, en su libro Introducción al Cristianismo, comentó un aforismo de san Ignacio de Loyola, que él recuerda como epígrafe con el cual el poeta alemán Hölderlin ilustra su Hyperion: "Non coerceri maximo, contineri tamen a minimo, divinum est". 
No ser cercado por lo máximo, no caber en la totalidad, y sin embargo ser contenido por lo mínimo, estar todo en lo mínimo, eso es divino².

Esto, que es una paradoja para la lógica filosófica, necesita un nombre, un lugar de experiencia, y lo encontramos repetidamente en el texto de Juan. Dios no es una idea superlativa tomada del poder, del conocimiento y de la riqueza que conocemos en este mundo. "Dios es amor" (1 Jn 4, 8.16). Aunque en la palabra "amor" hay polisemia, es decir, múltiples significados, e incluso significados contradictorios, cristiano es quien aprende, como discípulo de Jesús, lo que puede significar para Dios y para su acercamiento y revelación, la palabra "amor". Si Dios amó tanto al mundo que dio a su Hijo único para salvarlo, según esa misma lógica, Jesús ama y se entrega para la salvación del mundo: "Nadie tiene amor más grande que el que da su vida por los que ama" (Jn 15, 13).

Lo primero, por lo tanto, es que estamos ante la maravilla del modo como Dios se revela. En modo de amor, en el cual él renuncia a sí mismo para darnos espacio y venir a nuestro encuentro en la forma más generosa y despojada de sí mismo, suscitando nuestro "humanismo". Así también, Jesús, en la inminencia de su entrega, se puede presentar como "luz del mundo" (Jn 8, 12), aquel que, por su compasión, puede salvar al mundo de su odio ( $c f r$. Jn 4, 42).

\section{El odio del mundo al acercamiento de Dios: el lado escandaloso}

En segundo lugar, el escándalo. Hemos comenzado con una pregunta intrigante. ¿Por qué el mundo, que es suyo, que él ama y por el que él da su vida, no lo reconoce ni lo recibe? El texto de Juan no permite hacernos ilusiones sobre la forma de proceder del mundo. El mundo busca enredarse en la lógica del poder, del espectáculo, de la fama y, en última instancia, de la codicia y la ganancia. También los suyos, los más cercanos a Jesús, estando todavía en Galilea, tratan de convencerle de que abandone la periferia y vaya al centro: "Sal de aquí y vete a Judea para que tus discípulos vean las obras que haces, porque nadie actúa en secreto cuando quiere ser de conocimiento público. Si haces estas cosas, muéstrate al mundo" (Jn 7, 3-4).

Jesús desenmascara el oportunismo de sus discípulos, los intereses de poder que los mueven y los convierten en gente del mundo. Esa gente se encuentra bien en el mundo, es amada por el mundo, pero no Jesús, que se ha desvestido de todo interés propio y de oportunismo. Una religión del espectáculo y del poder, de "carrerismo" y de ventajas personales, una religión, en última instancia, de búsqueda y frenesí de ganancias, de usurpación, no es la religión de Jesús. En las tentaciones, los sinópticos narran cómo Jesús tiene que afrontar lo que le espera:

2. J. Ratzinger, Introdução ao Cristianismo, São Paulo, Herder, 1970, p. 105. 
cómo llevar a cabo su misión, que es la del Siervo de Yahvé, en los límites de su humanidad y en radical humildad.

La incompatibilidad con el mundo, por qué Jesús es odiado, se comprende mejor al ver el enfrentamiento entre Jesús y Pilatos. Es una confrontación entre el poder y la arrogancia sin verdad y sin justicia, y la verdad y la justicia sin poder. Ante el mundo de Pilatos, de su sistema de poder arbitrario, que no acepta su inocencia, Jesús confiesa: “¡Mi reino no es de este mundo! Si mi reino fuera de este mundo, mis súbditos habrían combatido para no ser entregado (...). $\mathrm{He}$ venido al mundo para dar testimonio de la verdad" (Jn 18, 36b.37b). En esta batalla desigual, Pilatos expresa las características del "príncipe de este mundo", mientras que las armas de Jesús son el amor hasta el final a este mismo mundo al que tanto ha amado el Padre.

En este trágico conflicto, el único poder de Jesús es el Espíritu de la verdad "que el mundo no puede recibir, porque no lo ve, ni lo conoce" (Jn 14, 17). Por eso tampoco conoce la paz que proviene del Espíritu, y sólo puede organizar una paz al estilo de Pilatos con la crueldad del poder que produce víctimas, la paz armada del imperio, el gobierno del "príncipe de este mundo" ( $c f r$. Jn 14, 27).

Estamos ante el escándalo y la tragedia de un mundo en tinieblas, que no se deja iluminar por la luz para que las obras de la injusticia sigan estando encubiertas, impunes y sagaces, y que aprisiona la verdad en la injusticia (cfr. Rm 1, 18b). Las tinieblas quedan encubiertas por la fascinación del espectáculo, de la celebración del poder y de la abundancia para los que siguen la lógica y el sistema del mundo, que, en los sótanos, esconde crucifixiones impuestas a inocentes para seguir siendo mundo. Pero en definitiva es un mundo de odio, que odia la verdad y todos los signos de otro mundo posible, es decir, signos de otra manera de ser mundo.

Los sinópticos detallan la profundidad el rechazo, incluso el religioso: no solo el mundo político, sino, lo que es más intrigante, también el mundo religioso, los líderes e instituciones religiosas, con los esquemas de los que practican la religión, han visto en Jesús una amenaza que debe ser eliminada. Pablo es categórico: "No os conforméis con los esquemas de este mundo" (cfr. Rm 12, 2), los cristianos, más bien, se han convertido "en espectáculo para el mundo" (1 Cor 4, 9). Un espectáculo al revés, espectáculo de sarcasmo y horror. Es lo que les ha sucedido a los mártires que no se han conformado con los juegos de este mundo inicuo.

A pesar de todo esto, ¿es posible otro mundo, otro modo de ser mundo, como es el sueño del Foro Social Mundial? 


\section{Un mundo para acercarse a Dios: otro mundo es posible}

Lo que hemos dicho hasta ahora parece hundirnos en el abismo de un dualismo irreconciliable, bien conocido en la refinada cultura occidental. Pero no tiene por qué ser así necesariamente, ni es así en los designios del Dios que tanto amó al mundo. Por lo tanto, la fe cristiana no puede ni debe sucumbir a esta tentación de dualismo.

Sabemos que este mundo, más precisamente el mundo que odia y mata a quien es de la verdad y a quien es justo e inocente, viene de Dios, es amado por Dios a pesar del odio. Y por amor a este mundo, Dios se da en Jesús, en la fragilidad, única fuerza del amor puro. Así, el amor vence al odio y hace caer al príncipe de este mundo. La victoria del inocente y amante del mundo, que fue injustamente ejecutado por el sistema cerrado del odio, consiste en vencer sin causar vencidos.

Cuando los oyentes de Pedro escucharon sus sorprendentes palabras: "A aquel del que renegasteis, el Justo que hicisteis morir, el Autor de la Vida que entregasteis a Pilatos, Dios lo justificó, lo resucitó" (Hch 3, 14ss), debieron quedar horrorizados: "Ahora viene la venganza divina, pues Dios está de parte del que hemos ejecutado". Pedro, sin embargo, llevado finalmente por el Espíritu Santo, repite lo que Jesús dijo en la cruz: "No sabían lo que hacían, pueden ser perdonados, alejándose de la vieja lógica del mundo y entrando en la lógica del inocente crucificado". Por eso Pedro les invita a convertirse y a sellar la conversión con el bautismo ( $c f r$. Hch 3, 17ss).

Esta es la victoria del martirio: vencer sin causar vencidos. No parece que eso sea posible, pues en toda victoria hay vencedores y vencidos. Pero el único camino para detener la trágica espiral de la violencia es entrar en la lógica de la victoria que no produce vencidos. Es una lógica martirial, es el poder y la fuerza de la víctima en relación a su verdugo, la víctima que puede rescatar al verdugo e inaugurar una lógica distinta, otro mundo posible. Es la manera de no despreciar al mundo, sino de acercarse a él y rescatarlo desde las víctimas, los humillados y aplastados por él. Es responder al odio con la fuerza del perdón y del amor exigente, a la violencia con la firmeza de la paz y el testimonio de que hay otra posibilidad de ser, de estar y de vivir en este mundo.

De este modo, siguiendo el texto de Juan, podemos entender por qué Jesús oró al Padre no para que saque a los suyos del mundo, sino para que, en el mundo, sean testigos de la verdad. Y conociendo bien la lógica del odio y la persecución, de los sufrimientos inocentes y del martirio, en esa misma oración Jesús da ánimo a sus discípulos: "Tengan valor. Yo he vencido al mundo" (Jn 16, 33b).

En esta victoria sin vencidos, todo el mundo puede participar como vencedor. Pero no ocurre por necesidad. Otro mundo sólo es posible. La verdad y el amor 
con que se libera y se redime el mundo son fruto de una libre decisión. También es posible permanecer y perecer en un mundo de odio.

La Pascua victoriosa de Cristo no produce una fascinación que seduce y que elimina la libertad. Es una invitación en libertad, serena y pacífica, para entrar en la nueva lógica, la lógica divina: No se convierte en espectáculo, ni se acerca con ostentación. Si Dios, en Jesús, se acercó al mundo en los márgenes, desde abajo, en la piel de los pequeños, entonces sabemos cuál es el lugar, no sólo de su revelación, sino también el lugar donde puede comenzar la Pascua de un nuevo mundo posible: en el reconocimiento, en la acogida y ayuda a los más pequeños, en la lucha por la vida de los que están más abajo, allá donde el mismo Dios está en el mundo. Obviamente, es esta una vocación arriesgada, especialmente para la Iglesia de los discípulos de Jesús.

Quiero terminar mi intervención recordando un hecho que pasó casi inadvertido con ocasión de la elección de Juan Pablo I. Entrevistado pocos días después, con humor dijo a los periodistas que la historia de la Iglesia no es exactamente la historia de los papas, sino la historia de los santos. Es cierto que hay santos entre los papas, aunque no todos. Lo que Juan Pablo I quería decir es más profundo: el corazón de la Iglesia, el hilo dorado de la historia de la Iglesia, no es la institución y quienes la encarnan, sino quienes aman al mundo y dan sus vidas por el mundo.

Para finalizar, recuerdo que en los inicios de los años ochenta, cuando yo era estudiante en la Universidad Gregoriana de Roma, tuve en mis manos un folleto sobre los sufrimientos en América Latina, sobre todo en los países de América Central en aquel preciso momento. Al final de un texto se podía leer: “(...) son centenas los laicos, catequistas, ministros de la palabra, militantes cristianos, curas... mártires de nuestro tiempo". Un compañero de estudios, al leerlo, expresó una duda: “Son mártires o son imprudentes?”. Mi reacción fue inmediata y acalorada: "Con prudencia, Jesús hubiera muerto de viejo en la cama, no en una cruz". La prudencia es una virtud humana y, por supuesto, cristiana. Pero puede ser también una actitud de los hijos de las tinieblas, cuando callar y esconderse es infidelidad y traición.

Hay situaciones en las que la fidelidad llama a superar lo que parecería prudencia. Y eso me llevó a volver a leer a san Agustín cuando analiza cómo distinguir el martirio del suicidio ${ }^{3}$. No era solo curiosidad mental. Es la necesidad de aclararse cuando surge una duda importante sobre la verdad, y sobre todo cuando el precio del testimonio es la pérdida de la vida. De hecho, san Agustín, entre la noble herencia de los estoicos, por una parte, y la herencia de años y años de mártires cristianos, por otra, recuerda que los estoicos presentan

3. Cfr. Agustín de Hipona, La Ciudad de Dios, XIX, 4. 
el suicidio, quitarse la vida, mejor dicho, desprenderse y despedirse de la vida, como la virtud más racional cuando ya no vale la pena vivir, o como diríamos hoy, cuando ya no hay "calidad de vida", incluida la vida política. Fue el caso de Sócrates y de Séneca. Como ocurriría hoy ante la falta de calidad de vida productiva o consumista, se retiraron.

No ocurre así con los mártires. En pleno vigor de sus vidas, no se retiran, sino que dan la vida. Mueren por aquello por lo que vale la pena vivir. Y con tal lealtad que, si por eso vale la pena vivir, también por eso vale la pena morir. Por decirlo al revés: ¡solo vale la pena vivir por aquello por lo que vale la pena morir! San Agustín termina sus reflexiones afirmando que el gesto de los estoicos no es un gesto de valentía, como aquéllos enseñaban, sino de cobardía.

Hoy sabemos que, dadas las complicaciones, sobre todo de carácter psicológico, no debemos comprender el suicidio necesariamente como acto de cobardía, pero sí es un gesto de retirarse, de pérdida trágica. Los mártires, al contrario - hay que subrayar con san Agustín - son amantes de la vida y de todo lo que es verdadera vida, ya que en definitiva solo vale la pena vivir por lo que vale la pena morir, y viceversa. Ir viviendo e ir muriendo es, ontológicamente, lo mismo.

Por eso son mártires: porque han amado al mundo y han dado intensa y decididamente su vida por el mundo. Así es su seguimiento de Jesús: amaron con fidelidad un mundo que les ha odiado, y no se callaron. A este mundo han dado testimonio de la verdad, sin temor de los que pueden matar. El mundo, no ellos, les ha quitado la vida del cuerpo. Pero, como monseñor Óscar Romero y centenares de mártires de nuestro tiempo, viven en el testimonio, en el amor con que Dios ama y rescata a este mundo.

Esto es ser cristiano. Ser del Reino victorioso de Jesús, que vence al odio del mundo, rompiendo el círculo del odio en el momento preciso de la entrega y de la aparente victoria del odio. De esta forma, el mismo mundo puede ser salvado en la Pascua de los mártires, inaugurando con signos muy cercanos el "otro mundo posible".

Permítanme finalizar con una exhortación de san Francisco de Asís, que viene al caso después de lo que hemos dicho:

Consideremos, hermanos, al buen pastor que ha dado su vida por sus ovejas. Los santos lo han seguido en la tribulación y en la persecución, en la vergüenza y en la tentación. Y sería una gran vergüenza para nosotros que los santos hayan hecho las obras y nosotros nos contentemos con contarlas y con eso recibir la gloria. ${ }^{4}$

4. Francisco de Asís, Exhortación, VI. 